\title{
Magnetic micro-solid-phase extraction based on magnetite-MCM-41 with gas chromatography-mass spectrometry for the determination of antidepressant drugs in biological fluids
}

\begin{abstract}
A new facile magnetic micro-solid-phase extraction coupled to gas chromatography and mass spectrometry detection was developed for the extraction and determination of selected antidepressant drugs in biological fluids using magnetite-MCM-41 as adsorbent. The synthesized sorbent was characterized by several spectroscopic techniques. The maximum extraction efficiency for extraction of $500 \mathrm{\varepsilon g} / \mathrm{L}$ antidepressant drugs from aqueous solution was obtained with $15 \mathrm{mg}$ of magnetite-MCM-41 at $\mathrm{pH} 12$. The analyte was desorbed using $100 \varepsilon \mathrm{L}$ of acetonitrile prior to gas chromatography determination. This method was rapid in which the adsorption procedure was completed in $60 \mathrm{~s}$. Under the optimized conditions using $15 \mathrm{~mL}$ of antidepressant drugs sample, the calibration curve showed good linearity in the

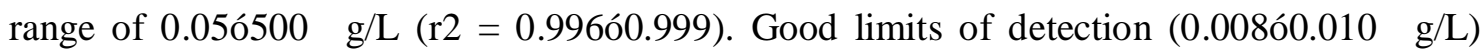
were obtained for the analytes with good relative standard deviations of $<8.0 \%(\mathrm{n}=5)$ for the determination of $0.1,5.0$, and $500.0 \mathrm{gg} / \mathrm{L}$ of antidepressant drugs. This method was successfully applied to the determination of amitriptyline and chlorpromazine in plasma and urine samples. The recoveries of spiked plasma and urine samples were in the range of 86.1ї $115.4 \%$. Results indicate that magnetite micro-solid-phase extraction with gas chromatography and mass spectrometry is a convenient, fast, and economical method for the extraction and determination of amitriptyline and chlorpromazine in biological samples.
\end{abstract}

Keyword: Antidepressant drugs; Biological puids; Gas chromatography-mass spectrometry; Magnetic micro-solid-phase extraction; Magnetite 